4 Hamilton Place, London, W.1. The new Apsley carriageway cutting across the corner of the Park is to be started soon and will give access to the site, but only while the road is under construction. The Society has seized this chance to launch an immediate appeal for the $£ 150,000$ needed to build and furnish a theatre seating more than 300 . The detailed plans are completed and open to inspection. All planning permissions are assured and it is hoped to start work this September. Donations should be sent to the Secretary of the Society at the above address

\section{Ultrasonic Vibrations at 10,000 megacycles}

AN announcement by the International General Electric Co., of New York, reports that one of its seientists, Dr. E. H. Jackson, has been able to produce ultrasonics at the enormous frequency of 10,000 megacycles per second. Up to the present, the limit of frequency has been about 200 megacycles per second, obtained from one of the high harmonics of a thin slice of quartz, excited piezoelectrically. Details of Dr. Jackson's method are not given, but it appears that a quartz crystal is combined with a cavity resonator in such a way as to excite it at a high frequency. The usual difficulty with such a device is to avoid the crystal jumping from one harmonic to another, but to prevent the ultrasonic energy degenerating into that associated with thermal vibrations in the material, the crystal is kept at $2^{\circ} \mathrm{K}$. It is proposed to use the source to investigate the energy-level of atoms and the interactions of electron spins in a crystal lattice. Another useful application -if the vibrations can be kept 'pure'-should be to study the absorption and velocity of ultrasonics in fluids with the view of finding very short relaxation times in the transfer of energy between the degrees of freedom of the molecules.

\section{South African Museum}

THE success of a museum as an educational centre is to a large extent dependent on a competent professional staff. The report of the South African Museum for 1957-58 (pp. 19. Cape Town: South African Museum, 1958) indicates that three posts for professional officers and a taxidermist which had been allowed to lapse have been revived and a new post of historian established. It is hoped that the creation of the latter post will lead to the formation of a Cultural-historic Museum in Cape Town. A new store has been built and the Museum is now in a position to accept historical material for safe keeping and subsequent exhibition. Unfortunately the staff are so fully occupied with normal curatorial work that they have little time for research, a function which is essential for the full development of a museum. The report includes notes on five new inseribed stones recently discovered on the site formerly occupied by the General Post Office in Cape Town.

\section{A New Field Centre}

ThE Field Studies Council is planning to open a sixth Field Centre during 1959. In co-operation with the Herbert Whitley Trust, a building and land are being acquired at Slapton in South Devon, and, in the first place, it is hoped to provide facilities for about thirty students. The Council has designated Mr. Ian Mercer, formerly assistant warden at Juniper Hall Field Centre, to the warden's post at the new centre. The property is situated at the seaward end of Slapton village about $400 \mathrm{yd}$. from the shingle of Start Bay. Behind the shingle bank are two large freshwater lakes-the Leys-which, together with Slapton Wood and France Wood, constitute a Nature Reserve which will be leased to the Field Studies Council by the Herbert Whitley Trust. There is considerable opportunity for biological fieldwork. It is hoped that the Centre can be opened for small parties in the near future and more fully from July 1, 1959.

Besides the new Centre, the annual report for 1957-58 (pp. $28+4$ plates. London: Field Studies Council, 1959) describes the continued growth and public demand for the existing Centres. Unlike previous issues, the annual report contains no scientific papers. In future, these are to be published independently under the new title, Field Studies. The first issue will include papers on the mollusca of the Flatford area; the insects of the Malham area ; the geography of the Alberbury breccia; and the geomorphology of the Tillingbourne.

\section{Architectural Science Review}

BUILDING is one of the traditional occupations of mankind which has become the subject of organized scientific inquiry only in comparatively recent times. In the early stages of research on building, attention was concentrated on the materials and constructions used, but latterly increased attention has been given to the overall problems of design. It is precisely with the scientific basis of architecture in the narrow sense of design for function that the new Australian journal, Architectural Science Review, is concerned (1, No. 1. Pp. 56. Three issues per year. Annual subscription, post free, 42s. (Australian) ; single copies, 15s. Academic Press Proprietary, Ltd., Sydney, Australia). The general scope of the Review is illus. trated by the papers in the first issue and by the titles proposed for the second. In the first issue there are papers concerned with thermal comfort zones, the weathering of buildings (with particular reference to curtain walls), the design of structures with the aid of models, building in the tropies, and daylighting design. In addition, a selective bibliography on climate and architecture is given. For the second issue, papers on the Australian climate, on lifts and escalators, and on high-alumina cements are proposed, in addition to two further papers on lighting and insolation. The Review promises to provide a focus for the publication of researches which at present are scattered in numerous scientific and architectural journals. A new journal covering the field is to be welcomed, and it may well attract papers from outside Australia.

\section{Kanamycin}

The New York Academy of Sciences has recently published, in the form of a monograph, laboratory and clinical results obtained with kanamyein in various centres in North and Central America ( $A n n$. N.Y. Acad. Sci., 76, 11; 1958. Article 2: The Basic and Clinical Research of the New Antibiotic, Kanamycin. By Maxwell Finland and 93 other authors. Pp. 17-408). Kanamycin is yet another Streptomyces antibiotic, which was discovered by $\mathbf{H}$. Umezawa and co-workers of Tokyo. Obtained from a new species Streptomyces kanamyceticus, kanamycin is basic and water-soluble, closely related chemically to neomycin and has some features in common with streptomycin; it consists of two amino-sugars linked glucosidally to 2-deoxystreptamine.

In vitro, kanamycin is active against many common pathogenic aerobic Gram-positive and Gram-negative 